\title{
MODERATING IMPACT OF POSITIVE EMOTION BETWEEN ACADEMIC STRESS, AND ACADEMIC PERFORMANCE OF STUDENTS: A CONCEPTUAL FRAMEWORK
}

\author{
Waqas Khuram $^{1^{\star}}$, Yanqing Wang ${ }^{2}$, and Aisha Khalid ${ }^{3}$ \\ ${ }^{1}$ Mr. Waqas Khuram School of Management, Harbin Institute of Technology, Harbin China, \\ waqaskhuram@hit.edu.cn \\ ${ }^{2}$ Prof.Yanqing Wang School of Management, Harbin Institute of Technology, Harbin China, \\ yanqing@hit.edu.cn \\ ${ }^{3}$ Ms. Aisha Khalid, School of Management, Harbin Normal University, Harbin China, \\ aishakhuram.19@gmail.com \\ "Corresponding Author
}

\begin{abstract}
Achieving desired performance in higher education tenure requires very hardworking and tireless efforts to meet the expectations and standards, such as students' tiring conditions often characterized by a high-stress level. Subsequently, the stress in academic settings is known to affect the individual adversely, and it is becoming essential to the student to perform under such stressful circumstances. Moreover, a high academic stress level may not affect an individual's performance with positive emotions toward their studies, courses, and other academic activities. Based on prior literature and rational opinions by students' academic stress levels in academic settings, such relationships may be moderated by the students' positive emotions that a student has.
\end{abstract}

Keywords: Academic Performance, Positive Emotions, Academic Stress

\section{INTRODUCTION}

Academic stress affects students' lives and negatively influences their mental and physical well-being and their capacity to do school work efficiently (Clark \& Rieker, 1986; Felsten \& Wilcox, 1992). The Academic Performance under stressful circumstances depends primarily on classes, competitiveness, expectative, and self-compliance, contributing to studying under pressure. In order to achieve good grades through high results, it is indispensable to concentrate on courses while learning and control feelings under pressure. Stress causes our emotions, however, and makes thinking and acting more than often very difficult. If the stress is intrigued, the brain restricts the capacity to think rationally and takes actions that can, in certain situations, contribute to irrational choices and poor results based on emotional behavior. In these circumstances, students must know how to avoid such poor performance in stressful situations and generate positive feelings or emotions that motivates them to face such stressful situations. Positive emotion, described as people who feel and express positive emotions, is more likely to function at optimal levels, and display greater results (Fredrickson, 2013). For instance, Oriol-Granado et al. (2017) state that positive emotions impact self-efficacy and education, predicting academic success. Earlier research indicates that people with positive emotions deal with experimentally induced stress more efficiently and that stress does not interfere with their cognitive performance, such as in resolving the problem anagram (Rosenbaum, 1980). These optimistic feelings are not inherently an inherited characteristic linked to birth and that individuals may inherit, not others (Khuram \& Wang, 2018). It is a cognitive perception and response process and cycles to the situation of human behavior and interference. In this study, we analyze literature on stress, positive emotions, affect student performance and present propositions with a conceptual framework based 
on previous literature, which suggests how positive emotions can alleviate the harmful effects of academic stress.

\subsection{Literature Review and Propositions}

\subsubsection{Academic Stress}

Stress is defined as a negative mental, cognitive, behavioural, and physiological cycle that arises when an individual attempt to cope with stressors. Stress is a required and unavoidable concomitant of everyday life, since we are described and apathetic beings without any pain, and inevitable whether it is fun or trigger for distress in conjunction with some external cause. Han Selye indicated that stress poses obstacles that inspire individuals to work hard and achieve their targets, while depression arises from the difficult circumstances that continue with time and create adverse health consequences (Landy \& Conte, 2016). In general terms, the optimal stress rates may help enhance the individual's efficiency, whereas unnecessary stress may reduce performance. Stress is both academic and social society has become an important topic. However, academic stress relates to parents', colleagues', and relatives' expectations create unnecessary pressure and stress on students to achieve their academic goals. Academic stress is a mental illness over any expected disappointment linked to academic failure or a feeling of imminent academic failure (Gupta \& Khan, 1987). Stress has been researched over a long time among students, and researchers have identified stressors as too many tasks, contests, failures, and poor relations with other students or faculty members. The most prevalent cause of stress for the students is academic issues. Familial tension, including divorce, intrapersonal dispute, and maternal distress, contribute to adaptive stress in young people (Hand, 1991). Khuram et al. (2017) and Schafer (1996) served that school stressors such as excessive research strain, too little room, writing term papers, taking innovation, future ambitions, and dull teachers typically pose the most unpleasant everyday threat. Students have been subject to academic stress because of the demand from parents, teachers, and students (Ang \& Huan, 2006). There are several approaches to deal with educational stress by graduates. Some people resort to avoiding relaxation, alcohol/drugs, depression, and psychological withdrawal, while others take the necessary steps to resolve academic stress effectively by recognition, preparation, and constructive reframing (Sreeramareddy et al., 2007).

\subsubsection{Academic Performance}

Students' academic performance is one of the most important post-graduate assessment indicators that educational scholars have in the last three decades taken into account study-related variables in order for curriculum administrators to devise effective measures for enhancing university efficiency. In the last few decades, higher education graduates' academic success has been the focus of demanding research. The performance is described as a person's actions observable or measurable in a particular circumstance, typically experimental. Performance measures the aspect of the behavior observed during a specific period. Students' performance (academic achievement) plays an essential part in producing the best graduates, who become the country's leading personnel and human resources, to contribute to economic and social development (Ali et al., 2013). However, some researchers conclude that students' academic performances depend upon their degree of learning adaptability. Accordingly, the academic performance of students globally assessed and evaluated by CGPA and subject grades or percentage secured by students during or at the end of the academic session; however, since research publication becomes a degree completion requirement in higher education institutions, the coursework (CGPA) and research performance (publications) are used to assess and evaluate the overall student's performance.

Therefore, research conducting activities sometimes needs tireless efforts and consistency to get optimum and quality results. In return, students who failed to get optimum results in any stage of research-based activities feel discomfort, which ultimately affects their overall performance. Researchers and scholars want to investigate the causes that influence student performance and create learning discomfort (Príncipe, 2005). Such discomforts and underperformance may be the cause of negative feelings from which an individual feels stress. The main objective, a comprehensive review of students' academic performance, will help establish a student support strategy and enhance teaching and preparation practices. Institutes can be involved in recognizing the student academic performance predictors in this regard. As a result, several predictors have been developed to assess performance ( $\mathrm{Li}$ et al., 2010), influencing university performance. These factors are classified into academic, psychosocial, cognitive, demographic Categories.

\subsubsection{Positive Emotions}

Positive emotions study has improved following the rise and growth of Positive Psychology. The theoretical model of (Fredrickson, 2001) is significant for the analysis of positive emotions. The theory's central premise 
is that positive emotions broaden the spectrum of feeling, behavior, desire, and temperament that spontaneously come to mind. Therefore, his model illustrates why positive feelings are necessary to strengthen physical, mental, psychological, and social capital to deal with such that potential adverse circumstances and crises. Fredrickson (2001), further claimed that positive emotions could produce permanent and healthy personal resources. Such, Positive emotions are short, multisystem reactions to any shifts in the perception or gratitude of people. While the presence of various kinds of positive emotions makes it necessary for us to determine how positive affectivity (a collection of positive emotions) predominates in people globally, this makes them more responsive, imaginative, and versatile. More studies have also been conducted in recent years, especially for students in academia, concerning the benefits of positive emotions. This form of emotion is known to be academic emotions (e.g., students), because they connect with behavior in schools or learning results (e.g., performance and failure) (Pekrun, 2009). Certainly, several of these studies have shown that having positive emotions, such as happiness, hope, or pride, facilitates the creation of self-regulatory coping approaches, greater commitment, and further academic success by students (Pekrun, 2009). The students will appreciate and draw their interest in the emotional feelings in a classroom. Previous literature suggests that positive emotions can play a significant role in understanding how students build their resources. That is because positive emotions are correlated with actions that build upon solutions. This means that if students are in a good mood, they can consider different situations, connect with others, have higher expectations for academic objectives, and pursue new goals.

\subsubsection{Academic Stress and Academic Performance}

Study-related Stress, refers to the stress faced by a person during his/her academic tenure and known as academic stress. Uncomfortable emotional conditions arising from the academic demands of parents, professors, workers, and family members apply to academic stress. The most frequent causes of stress for students have been academic problems. Precisely, Gupta and Khan (1987), defines academic stress as a psychological disorder in conjunction with potential disappointment due to academic failure or just future failure knowledge. Struthers et al. (2000) have stated that lower grades are associated with a high degree of academic stress. The high degree of academic stress is induced by exams, assignments, time, grade pressure, and uncertainty. This burden has a negative influence on their academic performance. According to Felsten and Wilcox (1992), university students' stress levels and academic successes are negatively associated. Blumberg and Flaherty (1985) observed an inverse relationship between self-reported stress levels and academic performance. Previous research has reported a detrimental and significant association of academic achievement with all levels of stress; nevertheless, findings have shown that higher stress is correlated with lower academic performance. Since the students' high performance is considered to be better performing and practical learning, therefore, consistent with the previous studies' arguments, we propose that high levels of stress may impede academic performance; thus, the following propositions are presented.

\section{Proposition 1: Academic stress will be negatively associated with academic performance.}

\subsubsection{Positive Emotions as Moderator}

Positive emotions are most significant, while individuals are under stressful conditions or situations, as positive emotions are more prevalent to more resilient persons. If they are weak in resilience, they have trouble controlling negative emotions and displaying an increased reactivity to normal challenging circumstances. Several studies have argued that resilience is an essential individual characteristic that mitigates the adverse effects of stress, also noticed that positive emotions alleviate the impact of stress on burnout and audit results. A similar study conducted by Cai et al. (2017) on Chinese soldiers indicated that positive feelings playing a vital role in reducing the negative impact of stress among Chinese troops. Moreover, the negative relationship between stress and positive emotion has also been reported (Smith \& Emerson, 2017). (Moskowitz \& Epel, 2006) investigated the role of positive emotion as a moderator and concluded that the everyday positive emotional engagement with life, appreciation, and spiritual improvement is significant; however, such as Hou et al. (2017), found that resilience moderated the relationship between stress and problematic social networking site usage such that the relationship was positive for those with low levels of resilience but non-significant for highly resilient individuals. It was centered on the outcomes of previous research. Therefore, it is rational to say that positive emotion may also moderate the relationship between an individual's academic stress and academic performance. The following propositions are then brought forward:

Propositions 2: Positive emotions will moderate the relationship between academic stress and academic performance such that the negative relationship between stress and academic performance will be weaker for those with high positive emotions and stronger for those with low and negative emotions. 


\subsection{The Conceptual Framework}

Figure 1. demonstrates the conceptual framework that reflects the propositions. As shown in the conceptual framework, it is proposed that academic stress would affect the academic performance of the students, and positive emotions are proposed to moderate the relationship between academic stress and academic performance. This methodological structure is suggested for analytical research in future studies. We urge researchers to test this conceptual framework for future research empirically.

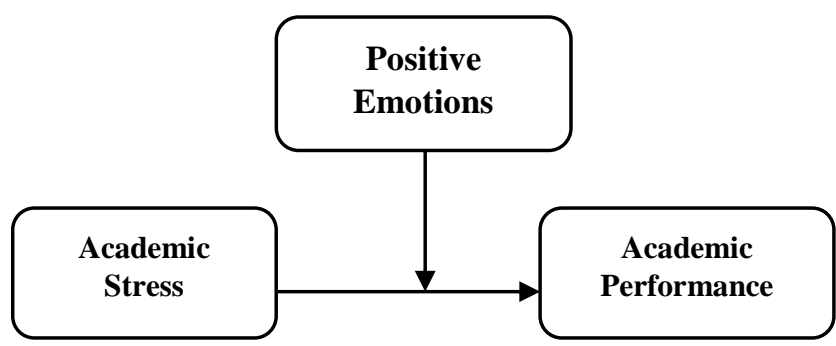

\section{Fig 1. Conceptual Framework}

\subsection{Conclusion and Future Research Implications}

Although past studies analyzed the relationship between academic stress and positive performance, however, the best of our knowledge, none of the studies has explored the moderating role of positive emotion in the relationship between academic stress and academic performance. Based on previous literature and logical reasoning, this research proposed investigating the moderating role of positive emotions in linking academic stress and academic performance, which is overlooked in previous studies. We believe that high academic stress will hinder students' academic performance, leading to unwanted consequences. However, when high academic stress is prevalent, positive emotions will overcome these undesirable effects and lead to better performance. Future analytical experiments will need to be carried out in order to determine whether or not such propositions are validated and verified by evidence. If it will become valid in future studies, it becomes mandatory for individuals, organizations, and communities to put collective efforts into building a high level of positive feelings and reducing the negative consequences of stressful circumstances.

\section{AUTHORS' CONTRIBUTIONS}

The title "WAQAS KHURAM AND AISHA KHALID" conceptualized the initial idea and reviewed related literature and find gaps; YANQING WANG provides the basic guideline and resources in finalizing this research.

\section{ACKNOWLEDGMENTS}

This research was financially supported by the NATIONAL NATURAL SCIENCE FOUNDATION OF CHINA (Grant NO. 71573065 and Grant NO. 71571085).

\section{REFERENCE LIST}

Ali, Shoukat, Haider, Zubair, Munir, Fahad, Khan, Hamid, \& Ahmed, Awais. (2013). Factors contributing to the students academic performance: A case study of Islamia University Sub-Campus. American journal of educational research, 1(8), 283-289.

Ang, Rebecca P, \& Huan, Vivien S. (2006). Academic expectations stress inventory: Development, factor analysis, reliability, and validity. Educational Psychological Measurement, 66(3), 522-539.

Blumberg, Phyllis, \& Flaherty, Joseph A. (1985). The influence of noncognitive variables in student performance. Journal of Medical Education.

Cai, Wen-peng, Pan, Yu, Zhang, Shui-miao, Wei, Cun, Dong, Wei, \& Deng, Guang-hui. (2017). Relationship 
between cognitive emotion regulation, social support, resilience and acute stress responses in Chinese soldiers: Exploring multiple mediation model. Psychiatry research, 256, 71-78.

Clark, Elizabeth J, \& Rieker, Patricia P. (1986). Gender differences in relationships and stress of medical and law students. Journal of Medical Education.

Felsten, Gary, \& Wilcox, Kathy (1992). Influences of stress and situation-specific mastery beliefs and satisfaction with social support on well-being and academic performance. Psychological Reports, 70(1), 291-303.

Fredrickson, Barbara L. (2001). The role of positive emotions in positive psychology: The broaden-and-build theory of positive emotions. American psychologist, 56(3), 218.

Fredrickson, Barbara L. (2013). Positive emotions broaden and build. In Advances in experimental social psychology (Vol. 47, pp. 1-53): Elsevier.

Gupta, Kiran, \& Khan, Badarun N. (1987). Anxiety level as factor in concept formation. Journal of Psychological Researches.

Hand, Rex Fore. (1991). The Role of Family Stressor and Parent Relationships on Adolescent Functioning. University of Gerogia. Journal of the American Academy of Child Adolescent Psychiatry, 30(2), 316.

Hou, Xiang-Ling, Wang, Hai-Zhen, Guo, Cheng, Gaskin, James, Rost, Detlef H, Wang, Jin-Liang \%J Personality, \& Differences, Individual. (2017). Psychological resilience can help combat the effect of stress on problematic social networking site usage. 109, 61-66.

Khuram, Waqas, Bhutto, Arabella, \& Jabeen, Arifa. (2017). Analyzing the Impact of Higher Education Commission Policies on Motivation of the Faculty Member of Jamshoro Education City. International Journal of Academic Research in Business Social Sciences, 7(6), 2222-6990.

Khuram, Waqas, \& Wang, Yanqing. (2018). Sharing Knowledge through Sharing Advisor in Age of Sharing Economy: A Conceptual Model. Paper presented at the 2018 International Conference on Economics, Business, Management and Corporate Social Responsibility (EBMCSR 2018).

Landy, Frank J, \& Conte, Jeffrey M. (2016). Work in the 21st century: An introduction to industrial and organizational psychology: John Wiley \& Sons.

Li, Gang, Chen, Wei, \& Duanmu, Jing-Lin (2010). Determinants of international students' academic performance: A comparison between Chinese and other international students. Journal of Studies in International Education, 14(4), 389-405.

Moskowitz, Judith Tedlie, \& Epel, Elissa S. (2006). Benefit finding and diurnal cortisol slope in maternal caregivers: A moderating role for positive emotion. The Journal of Positive Psychology, 1(2), 83-91.

Oriol-Granado, Xavier, Mendoza-Lira, Michelle, Covarrubias-Apablaza, Carmen-Gloria, \& Molina-López, Víctor-Michel. (2017). Positive emotions, autonomy support and academic performance of university students: The mediating role of academic engagement and self-efficacy. Revista de Psicodidáctica (English ed.), 22(1), 45-53.

Pekrun, Reinhard. (2009). Global and local perspectives on human affect: Implications of the control-value theory of achievement emotions.

Príncipe, Herminio Rodríguez. (2005). Factors influencing students' academic performance in the first accounting course: A comparative study between public and private universities in Puerto Rico. Argosy University/Sarasota.

Rosenbaum, Michael (1980). A schedule for assessing self-control behaviors: Preliminary findings. Behavior therapy, 11(1), 109-121.

Schafer, W. (1996). Passing the test of college stress. Stress management for wellness (pp. 543-563). In: Orlando: Harcourt Brace.

Smith, Kenneth J, \& Emerson, David J (2017). An analysis of the relation between resilience and reduced audit quality within the role stress paradigm. Advances in accounting, 37, 1-14.

Sreeramareddy, Chandrashekhar T, Shankar, Pathiyil R, Binu, VS, Mukhopadhyay, Chiranjoy, Ray, Biswabina, \& Menezes, Ritesh G \%J BMC Medical education. (2007). Psychological morbidity, sources of stress and coping strategies among undergraduate medical students of Nepal. 7(1), 26. 
Proceedings of INTCESS 2021 8th International Conference on Education and Education of Social Sciences 18-19 January, 2021

Struthers, C Ward, Perry, Raymond P, \& Menec, Verena H (2000). An examination of the relationship among academic stress, coping, motivation, and performance in college. Research in higher education, 41(5), 581-592. 